\title{
Overtube-assisted placement of a capsule endo- scope in a patient with a swallowing disorder
}

Small-bowel video capsule endoscopy (VCE) is generally contraindicated in patients with swallowing disorders. However, it is difficult to judge the ability of patients to swallow a capsule endoscope before examination and accidental aspiration of capsule endoscopes has been reported [1-3]. Previously, it was reported that overtube-assisted VCE placement was useful $[4,5]$.

A 64-year-old man underwent VCE for investigation of hypoproteinemia. He had reduced oral intake because of a 1-month history of gastrointestinal bleeding and his ability to swallow a capsule endoscope could not assessed before the examination. He had undergone pancreatoduodenectomy for bile duct cancer 52 months previously, and his performance status was grade 3.

During VCE, the capsule endoscope was accidentally aspirated into the bronchus and the main bronchus was imaged in real time ( $\bullet$ Fig. 1). Fortunately, the capsule remained in the main bronchus and he immediately regurgitated it without experiencing dyspnea. On the same day, endoscopic placement of a capsule endoscope into his stomach was performed using an esophageal overtube (TOP Corporation, Tokyo, Japan).

The patient was sedated with $1.5 \mathrm{mg}$ midazolam intravenously and an endoscope was inserted through the overtube to confirm its placement beyond the cervical esophagus. The endoscope was withdrawn. The capsule endoscope was then inserted into the overtube ( $\bullet$ Fig. 2 ) and pushed through the stomach to the anal side of the anastomosis using forceps ( $\mathbf{F i g . 3}$ ). The total procedure time was only 6 minutes. Although the capsule did not reach the colon, swelling of Kerckring's folds and minor mucosal bleeding were noted, which indicated amyloidosis ( Fig.4). There were no complications during the procedure.

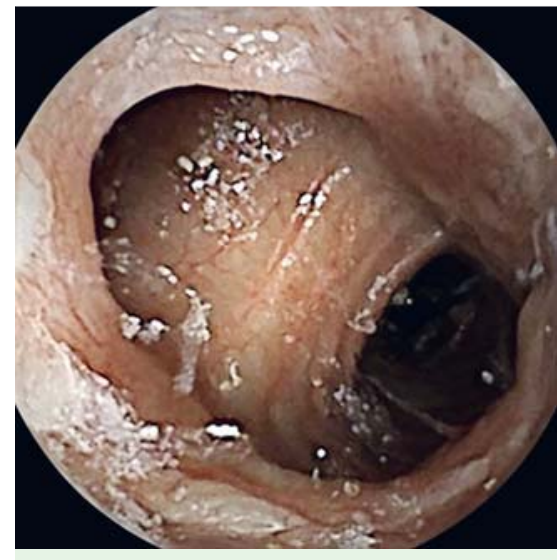

Fig. 1 A capsule endoscopic image showing the main carina.

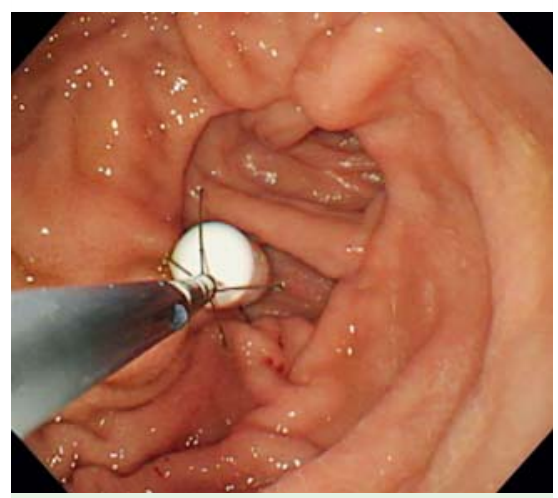

Fig. 3 Endoscopic image showing the capsule endoscope being pushed to the anal side of the anastomosis using forceps.

Overtube-assisted placement of a capsule endoscope can be the first choice in patients with swallowing disorders because of the good visibility, reliability, and safety offered. Additionally, if gastrointestinal hypomotility is expected, this method can be used to decrease the gastric and small-intestinal transit time.

Endoscopy_UCTN_Code_CPL_1AI_2AB

Competing interests: None

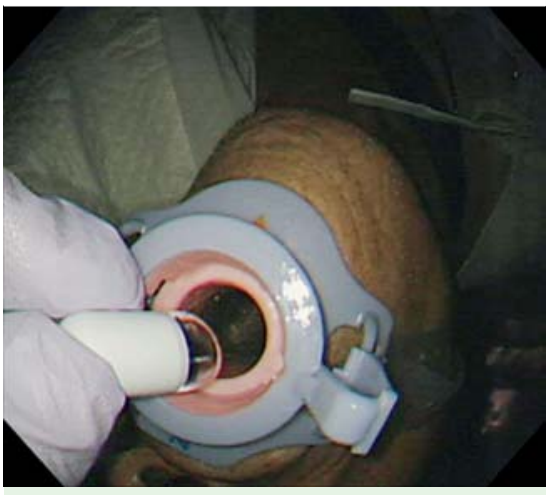

Fig. 2 The capsule endoscope is placed into the overtube by hand.

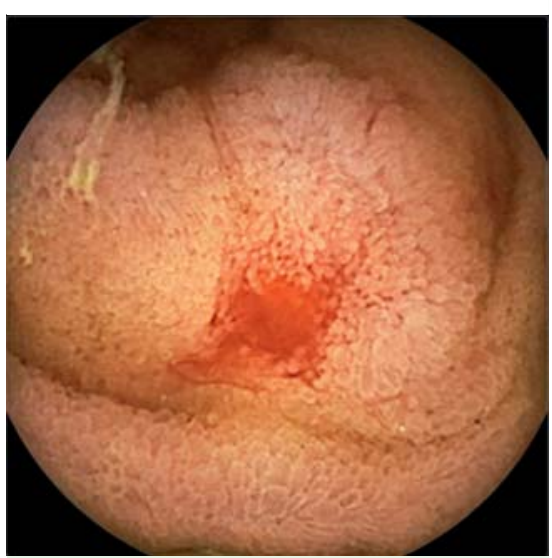

Fig.4 A capsule endoscopic image showing swelling of Kerckring's folds and minor mucosal bleeding.

Sayo Ito, Kinichi Hotta, Kenichiro Imai, Hiroyuki Ono

Division of Endoscopy, Shizuoka Cancer

Center, Shizuoka, Japan

\section{References}

1 Amarna M, Vanlandingham A, Brahmbhatt $P$ et al. Late presentation of capsule endoscope aspiration with successful extraction by flexible bronchoscopy utilizing a snare wire loop. Endoscopy 2015; 47 (Suppl. 01): E6E7 
2 Ding NS, Hair C, De Cruz P et al. Education and Imaging. Gastrointestinal: symptomatic bronchial aspiration of capsule endoscope a significant complication. J Gastroenterol Hepato 2013; 28: 761

3 Soncini $M$. Rare complication during videocapsule endoscopy. Dig Endosc 2012; 24: 280

4 Ouan C, Chen G, Lee-Henderson M et al. Overtube-assisted placement of wireless capsule endoscopy device. Gastrointest Endosc 2005; 61: 914-916

5 Holden JP, Dureja P, Pfau PR et al. Endoscopic placement of the small-bowel video capsule by using a capsule endoscope delivery device. Gastrointest Endosc 2007; 65: $842-$ 847
Bibliography

Dol http://dx.doi.org/

10.1055/s-0042-100808

Endoscopy 2016; 48: E47-E48

(c) Georg Thieme Verlag KG

Stuttgart · New York

ISSN 0013-726X
Corresponding author

Sayo Ito, MD

Division of Endoscopy

Shizuoka Cancer Center

1007 Shimonagakubo

Nagaizumi, Sunto-gun

Shizuoka, 411-8777

Japan

Fax: +81-55-9895783

sa.ito@scchr.jp 